Saudi Journal of Oral and Dental Research

Abbreviated Key Title: Saudi J Oral Dent Res

ISSN 2518-1300 (Print) | ISSN 2518-1297 (Online)

Scholars Middle East Publishers, Dubai, United Arab Emirates

Journal homepage: https://saudijournals.com

\title{
Oral Health and Oromotor Skills of Children with Cerebral Palsic Infirmity in the City of Yaounde
}

Mbede Nga Mvondo Rose ${ }^{1 *}$, Mbassi Awa Hubert Désiré ${ }^{1}$, Lowe Jacqueline Michèle ${ }^{1}$, Matongo Makon Paul Christel ${ }^{1}$, Koupouapouognigni Njumemi Sodetou ${ }^{1}$, BengondoMessanga Charles ${ }^{1}$

${ }^{1}$ Faculty of Medicine and Biomedical Sciences of the University of Yaoundé 1-Cameroon

DOI: $10.36348 /$ sjodr.2022.v07i01.010

| Received: 09.12.2021 | Accepted: 20.01.2022 | Published: 30.01.2022

*Corresponding author: Mbede Nga Mvondo Rose

Department of Oral, Maxillofacial and Periodontology Surgery at the Faculty of Medicine and Biomedical Sciences, Yaounde, Cameroun and Info Maladie Rare, Yaounde, Cameroun

\section{Abstract}

Introduction: Cerebral palsy is a disorder due to non-progressive brain damage on an immature brain, occurring before, during or after birth. Oral repercussions are often present but overlooked. Hence, the description oral health and oral motor skills of children affected by this condition. Methods: A descriptive cross-sectional study was conducted for eight months, in two specialized centers in the city of Yaoundé. Information was collected from medical records, consents obtained and oral examination of patients performed. The significance threshold was considered for $\mathrm{p}<0.05$. Results: Of the 60 patients included, 56.7\% suffered from spastic hemiplegia, 50\% had a level III gross motor classification system (GMFCS) and $28.3 \%$ had a level II. Their oral condition and oral-motor dexterity revealed salivary and labial incontinence, poor oral hygiene in $28.3 \%$ of cases, severe gingival inflammation in 34 patients $(56.7 \%)$, the loss of part of the food ingested in 50 patients $(84 \%)$ and swallowing and phonation disorders, respectively in $88.3 \%$ of cases and swallowing. A significant association between the severity of BMI and the occurrence of caries $(\mathrm{P}=0.001)$ and gingivitis $(\mathrm{P}=0.01)$. Conclusion: Oral health and oral motility of IMC patients is a function of the severity of brain damage. This oral state, requiring a specialized odontostomatology follow-up adapted to the handicap presented by the patient.

Keywords: Health, oral health, skill, oromotor, children, cerebral palsy.

Copyright $\odot \mathbf{2 0 2 2}$ The Author(s): This is an open-access article distributed under the terms of the Creative Commons Attribution 4.0 International License (CC BY-NC 4.0) which permits unrestricted use, distribution, and reproduction in any medium for non-commercial use provided the original author and source are credited.

\section{INTRODUCTION}

Cerebral palsy is a disorder of posture and movement due to brain damage that can occur in the immature brain, pre, per and postnatal [1]. In pediatrics, the incidence of feeding and swallowing difficulties is very high and even more so in certain populations at risk such as children with cerebral palsy, neurodevelopmental delays or children born prematurely. These difficulties, if they are significant and lasting, can have effects on the good development of children and have an impact on their long-term life, on growth, cognitive development, behavior, or chronic respiratory disorders [2]. There are generally two types of disorders: eating disorders, which affect the various feeding activities, behavior and food environment; and swallowing disorders resulting from a dysfunction in the swallowing sequence and the main risk of which is the penetration of part of the food bolus into the respiratory tract [3]. Throughout the world, several studies have been made about the oromotor ability of children with IMC. Which remains rare in Africa. Nevertheless, Mbassi et al., In Cameroon, already mentioned in 2018, the presence of periodontal disease and carious lesions in 242 patients with this category of disability [4]. Their general condition, often leading to the neglect of their oral health, often impacted by the disorders associated with their disability. This is the reason why our study proposes to evaluate the ability of patients to achieve their orality according to the state of their oral cavity and the severity of their cerebral palsy. This will make it possible to define the needs and the specific circuit of oral care for these patients.

\section{MATERIALS AND METHODS}

We conducted a cross-sectional and descriptive study within two specialized, reference centers of the city of Yaoundé: Mother and Child Center of the Chantal Biya Foundation (CME-FCB) and the National Center for the Rehabilitation of Persons with 
Disabilities Cardinal Paul Émile (CNRPH). The study was carried out over a period of eight months, from January 2021 to August 2021. The choice of these two sites was justified by the existence of pediatric neurology consultations (CME-FCB) and the presence of specialized paramedical staff (CME-FCB andCNRPH). Sampling was non-probability and consecutive. Was included in our study, any subject with cerebral palsy, registered in the registers of the reference centers mentioned above, complaining of oral symptoms or not, and whose parent or guardian had given informed consent for participation. of the patient under study. Patients who died or were lost to follow-up were excluded from our study. We then contacted the parents or guardians of the patients by telephone, for a telephone or face-to-face interview, during which information on all aspects of the study was given to them. Their informed verbal and written consent was collected and it was then that we finally proceeded to recruit patients. Patient consent was also required. when the patient's age and mental state permitted. Subsequently, an interrogation and a specific detailed physical examination were carried out. The data collected included: socio-demographic information such as age, sex, level of education, place of residence and region of origin. The family history of identical disease, the type of BMI and the severity rate of the BMI according to the GMFCS, the personal history of oral affections, consultation of genetics or stomatology. Then, the description according to the OMAS classification of the type of mastication, the oromotor skill were evaluated, thanks to the food croissants and yogurt which had been given to them, at the same time the swallowing was also evaluated. Breathing was examined, via the labial incompetence observed in the latter and the dental mirror placed near the nostrils made it possible to see whether the latter was covered with vapor from gas exchange or not. Regarding sucking, the parent was asked if the child sucked his finger or the pacifier. The salivation was evaluated thanks to the piece of sugar placed in the oral cavity and to evaluate the time of dissolution (sugar test) and finally the parodontopathies and carious affections were detected. The data collected for each patient was marked on a previously tested form. Participants with oral abnormalities, hard or soft tissue infections, or oralmotor disorders were referred to a specialist consultation. Traveling cost for patients as well as their parents or guardians related to our studies were reimbursed. This work had obtained the ethical clearance of the institutional Committee of Ethics and Research of the Faculty of Medicine and Biological Science of the University of Yaoundé 1. Similarly, all the necessary administrative clearance had been obtained. The principles of confidentiality, harmlessness, respect of the dignity and integrity of patients of Helsinki declaration marked all the stages of this study. The information collected was entered using a data entry mask designed with CSPro6.1 software. It was analyzed using SPSS version 25.0, and the diagrams, figures, and tables were produced using Microsoft Excel 2007. The Chi-square text was used to compare proportions and correlations. A p-value $<0.05$ was considered significant.

\section{RESULTS \\ Description of socio-demographic profile and dental history}

Of the 72 IMC patients listed in the registers of the aforementioned specialized centres, 12 patients were excluded and 60 retained for the remainder of the study. After collection of consents and counting of those lost to sight and deceased. 42 children, or $70.0 \%$ of our target, were between one and five years old. The male sex was predominant with $38(63.3 \%)$ cases, i.e. a sex ratio of 1.7 .

Regarding schooling, only 12 attendees $(20.0 \%)$, were educated in a specialized environment.

\section{Disorders associated with BMI}

Epilepsy with two cases (3.3\%), was the only co-morbidity associated with BMI in these patients.

\section{Classification of motor skills}

22 patients $(36.6 \%)$ were able to walk in most situations or climb stairs while holding on to the railing (global motor function level 1 and 2). In addition, 38 participants, or $63.3 \%$, had mobility limitations and required physical assistance or electrical/mechanical mobility with gross motor function levels 3 and 4.

\section{Types of paralysis}

Childhood cerebral hemiplegia with 34 patients (56.7\%), was the most common topographic form of CMI, followed by quadriplegia with 18 cases $(30 \%)$.

\section{Ventilation and phonation}

Regarding functional disorders, we have objectified bucco-nasal ventilation (16 patients for $26.7 \%$ ) and phonatory difficulties (37 patients for $61.7 \%)$.

\section{Salivation and parafunctions}

Patients had salivary incontinence in 43 cases (71.7\%). 34 cases $(56.7 \%)$ were drooling, 31 cases $(51.7 \%)$ were bruxing and 24 patients suffered from both drooling and bruxism.

\section{Sucking, chewing and swallowing}

Confounded sucking of the pacifier, finger and tongue emerged in 30 cases $(50 \%)$. Alternate chewing with 55 patients $(91.7 \%)$ as well as primary swallowing (40 patients for $66.7 \%$ ) were noted in our study population

\section{Feeding routes}

All participants had an oral diet 


\section{Evaluation of lip closure on utensil}

26 participants (43.3\%) closed their lips unsatisfactorily, with partial loss of food, 25 patients closed their lips properly on the utensil, with complete elimination of food, and nine cases were unable to close their lips on the utensil. utensil, while clenching it with your teeth.

\section{Assessment of lip closure during swallowing}

During swallowing, 26 patients $(43.3 \%)$ had incorrect lip closure, without lingual interposition, 27 others were able to close the lips well and seven $(11.7 \%)$ were unable to close the lips, with tongue interposition.

\section{Assessment of food control during swallowing}

Regarding the control of food during swallowing, 29 cases $(48.3 \%)$ had poorly controlled movements of the tongue, with loss of part of the food during meals, $23(38.3 \%)$ patients did not lose food during swallowing and the bottom eight still lost almost all the food they put in their mouths (Figure 14).

\section{Evaluation of liquid control during swallowing}

During swallowing, 30 (50\%) and nine (15\%) lost respectively a small and a large part of the ingested liquids. Nevertheless, 21 (35\%) did not let it escape.

\section{Assessment of straw suction}

During sucking, 31 subjects or $51.7 \%$ were unable to feed with a straw.

\section{Tooth and Skin Angle Classes}

Cutaneous and dental Angle classes 1 were in the majority, with 40 (66.7\%) and 48 (80.0\%) respectively.

\section{Oral Hygiene}

Most children (34 versus $56.8 \%$ ) had poor oral hygiene, according to the OHIS index.

\section{Periodontal Status}

The periodontium was mostly normal with 34 cases $(56.7 \%)$ with the presence in 25 patients $(41.7 \%)$ of gingivitis.

\section{Dental status of the population}

Only 17 patients $(28.3 \%)$ suffered from dental caries, with low CAOD and OD indices of 0.78 and 0.35 respectively. Thus, the CAODcod $(\mathrm{CAO}+\mathrm{co})$ index was 1.13 . 18 patients $(30.0 \%)$ had enamel hypoplasia.

\section{Correlation between degree of severity of BMI and gingivitis}

A statistically significant association $(\mathrm{p}=0.010)$ emerged between BMI severity level 1 and the occurrence of gingivitis. This observed difference was statistically significant (Table II).

Table II: Association between degree of severity of BMI and gingivitis

\begin{tabular}{|l|l|l|l|l|}
\hline \multirow{2}{*}{ BMI severity } & \multicolumn{2}{|l|}{ Gingivitis } & \multirow{2}{*}{ OR [95\% CI] } & p-value \\
\cline { 2 - 4 } & $\begin{array}{l}\text { Yes } \mathbf{N = 2 5} \\
\text { not (\%) }\end{array}$ & $\begin{array}{l}\text { No N=35 } \\
\text { not (\%) }\end{array}$ & & \\
\hline Level 1 & $5(20.0)$ & $0(0.0)$ & $/$ & $\mathbf{0 . 0 1 0}$ \\
\hline Level 2 & $4(16.0)$ & $13(37.1)$ & $0.3[0.1-1.1]$ & 0.065 \\
\hline Level 3 & $11(44.0)$ & $19(54.3)$ & $0.7[0.2-1.9]$ & 0.300 \\
\hline Level 4 & $5(20.0)$ & $3(8.6)$ & $2.7[0.6-12.4]$ & 0.184 \\
\hline
\end{tabular}

\section{Correlation between degree of severity of BMI and gingival hypoplasia}

The severity of BMI level 4 and gingival hypoplasia were related with $\mathrm{p}=0.045$ (Table III).

Table III: Association between degree of severity of BMI and gingival hypoplasia

\begin{tabular}{|l|l|l|l|l|}
\hline \multirow{2}{*}{ BMI severity } & \multicolumn{2}{|l|}{ Gingival hypoplasia } & \multirow{2}{*}{ OR [95\% CI] } & p-value \\
\cline { 2 - 3 } & Yes N=18 & No N=42 & & \\
\cline { 2 - 3 } & not (\%) & not (\%) & & \\
\hline Level 1 & $2(11.1)$ & $3(7.1)$ & $1.6[0.2-10.7]$ & 0.475 \\
\hline Level 2 & $3(16.7)$ & $14(33.3)$ & $0.4[0.1-1.6]$ & 0.159 \\
\hline Level 3 & $8(44.4)$ & $22(52.4)$ & $0.7[0.2-2.2]$ & 0.389 \\
\hline Level 4 & $5(27.8)$ & $3(7.1)$ & $\mathbf{5 . 0}[\mathbf{1 . 0 - 2 3 . 9}]$ & $\mathbf{0 . 0 4 5}$ \\
\hline
\end{tabular}

\section{Correlation between degree of severity of BMI and dental caries}

BMI severity level 1 was frequently associated with the occurrence of dental caries $(\mathrm{p}=0.001)(\mathrm{Table}$ IV). 
Table IV: Association between degree of severity of BMI and dental caries

\begin{tabular}{|l|l|l|l|l|}
\hline \multirow{2}{*}{ BMI severity } & \multicolumn{2}{|l|}{ Toothdecay } & \multirow{2}{*}{ OR [95\% CI] } & p-value \\
\cline { 2 - 3 } & Yes N=17 & No N=43 & & \\
\cline { 2 - 3 } & not (\%) & not (\%) & & \\
\hline Level 1 & $5(29.4)$ & $0(0.0)$ & $/$ & $\mathbf{0 . 0 0 1}$ \\
\hline Level 2 & $3(17.6)$ & $14(32.6)$ & $0.4[0.1-1.8]$ & 0.204 \\
\hline Level 3 & $8(47.1)$ & $22(51.2)$ & $0.8[0.3-2.6]$ & 0.5 \\
\hline Level 4 & $1(5.9)$ & $7(16.3)$ & $0.3[0.0-2.8]$ & 0.271 \\
\hline
\end{tabular}

\section{DISCUSSION}

The main objective of our study was to describe the oral status in patients with cerebral palsy and assess their oral motor skills. The exclusion of certain patients is the fact either of the refusal of parents to participate in our study and either of the loss of sight of patients

In this study, the percentage of boys with BMI represented $63.3 \%$ of children with a sex ratio of 1.7 . In Europe, Johnson A in 2002 on a study looking at the prevalence of children with cerebral palsy found more boys than girls with $\mathrm{CP}$ with a Boy:Girl ratio of 1.33:1 [5], In Sweden, Westbom L et al., in 2007 reported a boy sex ratio; 1.3/1000 [6] and in the United States Yeargin-Allsopp $\mathrm{M}$ et al., also reported a higher prevalence in boys than in girls (overall boy/girl ratio: 1.4:1) of higher than that of girls [7] this similarity could be explained by the choice of our type of sample and the size of the workforce which was 60 . This was not large enough, Also, $80.0 \%$ of patients were unschooled. This could be explained by the fact that some parents, given the reduced capacity for communication, intellectual aptitudes and the cost of schooling for children, would be reluctant to send their children to school. This explanation is superimposable to the findings of Jarl J et al., in 2020 who had observed that children with cerebral palsy, had considerably lower academic results than a sample of the general population of Sweden, Much of the difference could be attributed to the usually associated intellectual disability [8]. In our study, however, we would have expected that some patients would attend regular schools as part of the inclusive education advocated by the public authorities of our country.

The most represented age group was that of one to five years with a frequency of $70 \%$. This could be due to the fact that it is during this period that the diagnosis of cerebral palsy is often made, and paramedical and specialized rehabilitation treatment begins. It is also a time when parents are still hopeful about the prospect of improvement in their children. We can also mention the fact that they are more easily transported to treatment centres, compared to older children using walking aids or wheelchairs.

Speaking of diseases associated with BMI, apart from cognitive delay which had not been taken into account in our study, they were mainly represented by epilepsy, $3.3 \%$ of cases. Which is relatively low. Work shows that apart from epilepsy, early brain damage can be responsible for associated disorders such as: sensory disorders (deafness, low vision) and neurosensory (difficulties in visual, verbal, sensitive gnosis, etc.). .. Strabismus is common and often there are difficulties in tracking, fixing and tracking the eyes (opto-motor disorders); endocrine disorders (growth disorders, precocious puberty, etc.); behavioral and/or personality disorders. Oral disorders are also described and will be discussed later. Compared to our study, the number of patients with epilepsy was not superimposable to the findings in Europe of Mert G et $a l$. , in 2011 on the factors affecting the development of epilepsy or they found an incidence of epilepsy in patients with cerebral palsy ranging from 15-90\% [9]. This difference could be due to the fact that some parents no longer remembered or did not remember the previous problems encountered by the children following an improvement in their physical conditions (memory bias). This could also be due to a selection bias in our study epilepsy in patients with cerebral palsy ranging from $15-90 \%$ [9]. This difference could be due to the fact that some parents no longer remembered or did not remember the previous problems encountered by the children following an improvement in their physical conditions (memory bias). This could also be due to a selection bias in our study. epilepsy in patients with cerebral palsy ranging from 15-90\% [9]. This difference could be due to the fact that some parents no longer or did not remember the previous problems encountered by the children following an improvement in their physical conditions (memory bias). This could also be due to a selection bias in our study.

The level of severity of BMI in our study was assessed using the Global Motor Function scale according to Palisano. This showed us that the motor function in our participants was assessed at level 3 in $50 \%$ of cases according to the "GMFCS" and in $13.3 \%$ at level 4. So nearly two thirds of the patients had Cerebral Palsy $\mathrm{C}$ of moderate severity significant and justified their attendance at specialized care facilities. These results are not similar to those of numerous studies found, including that of Katherine A et al., in Australia, which had found a prevalence of $41.7 \%$ for level 3 according to the "GMFCS" [10] and Pinto V et al., in Brazil. which had a predominance at $37,14 \%$ for level 2 according to the "GMFCS" [11]. The differences observed could be due to the fact that 
children with more serious disorders were more eligible for physical rehabilitation or devices. However, the younger ones were easier to transport to the care services.

Regarding the distribution of paralysis according to topography, the form of paralysis most represented during BMI during our study was spastic hemiplegia $56.7 \%$. This is probably a selection bias (it would be related to the small size of our sample). This predominance is not usually observed. Indeed, in children with cerebral palsy, the most common forms are: spastic quadriplegia and diplegia as corroborated by the study in Chicago by Santos M et al., in 2005 on the development of motor functions in 116 cases of children patients with cerebral palsy showed that forms of spastic quadriplegia and diplegia were the most represented with $35 \%$ and $26 \%$ [12].

Speaking of oral functional status, ventilation in our patients was predominantly nasal, i.e. $73.3 \%$, this proportion was clearly similar to that found by Miamoto et al., in America who found that $70.2 \%$ of patients had nasal ventilation [13].

This similarity could be explained by the fact that most of the patients encountered did not have a nasogastric tube for feeding, which could cause breathing difficulties in children with cerebral palsy, or at least nasal discomfort.

Regarding the problem of salivation and para function, $71.7 \%$ of the participants had a problem of salivary incontinence, which is clearly higher than the findings of Tahmassebi and Luther who had indicated a possible association between the tightness of the lips and the presence of drooling in children with cerebral palsy attending special schools in the county of Yorkshire. In this work, two-thirds of the children who contributed suffered from drooling, $22.6 \%$ had frequent and severe drooling and $19.4 \%$ abundant and constant drooling of saliva [14]. This could be explained by the fact that there is no significant association between hyper salivation and cerebral palsy, which is similar to the study by Erasmus C et al., in 2009 which demonstrated that there is no hyper salivation in children with cerebral palsy who drool [15]. This would therefore be salivary incontinence linked to oral disorders in patients with normal saliva production.

The results of the present study also revealed that the association bruxism + drooling was the main para function encountered $40 \%$. These results are in agreement with the results of the studies of Ortega A et al., as well as Botti Rodrigues et al where a high prevalence of bruxism had been reported in people with cerebral palsy, and which was respectively $36.9 \%$ and $42 \%[16,17]$. This could be due to a neurological impairment causing involuntary and repetitive movements in patients with cerebral palsy. It could also be a function of the topographic shape of the BMI; in fact, in spastic quadriplegics, the rate of bruxism was very high, as shown by the study by Peres A et al., in 2007 in Brazil [18].

The evaluation of oral oral performance according to OMAS in patients with IMC showed that $43.9 \%$ of our children were classified in the category of underfunctional oral motor skills and $36.93 \%$ were classified in the category functional oral motor skills. Our results are similar to those of Botti Rodrigues et al who reported a high prevalence of subjects with underfunctional oral motricity $64.7 \%$ against $35.25 \%$ for those with optimal functional motricity [17]. The similarities between the studies could be explained by the fact that most of the patients were followed in specialized structures for multidisciplinary management, hence a certain improvement in oral motor skills.

Most of the items evaluated found the existence of difficulties at different stages of the food or liquid intake process; labial continence after placing the utensil in the mouth, effective intake of the food or liquid offered without loss, chewing, lingual skills in kneading and propulsion of the food bolus towards the pharynx for swallowing, functioning harmony of the aerodigestive crossroads. In this subcategory of patients, it is likely that the quantities of food and nutritious liquids ingested are insufficient to ensure optimal height and weight growth. Furthermore, the recurrence of aspiration could compromise pulmonary status through frequent aspiration pneumonia.

Regarding oral hygiene, we found that most children had poor oral hygiene, ie $60 \%$ of cases. These results approach the $40 \%$ found by Preetika et al., in 2011 [19]. This could be explained by the fact that the more severe the neurological damage, the higher the incidence of the bite reflex and, therefore, the more the risk of oral disease is high in children with spastic CP. We can also mention the difficulties of implementing adequate oral hygiene as demonstrated by Dos Santos $\mathrm{M}$ et al in 2005 in Brazil [20].

More than $84 \%$ of our patients suffered from periodontal disease ( $43 \%$ of children had an abnormal periodontal state and $41.7 \%$ of children had gingivitis). Double percentage in the study by de Mbassi et al., in Cameroon, who reported that gingivitis was the predominant periodontal lesion. It was found in $72.6 \%$ of their patients and periodontal anomalies in $83.1 \%$ of these patients [4]. Indeed, this difference could be due to the multiplicity of disabilities listed during his study, while ours only described BMI patients.

The prevalence of caries is quite low in our series $28.3 \%$ with a CAODcod index (CAOD + cod) of 1.13. This result is comparable to those of Nqcobo in South Africa [21] or Chand in India [22] who found a 
prevalence of around $30 \%$. In these studies, the children attended specialized institutions, and benefited from medical supervision, and from a balanced diet with controlled intake of refined carbohydrates. However, compared to general population data Kamate D had reported an overall caries prevalence of $74.31 \%$ and a CAO index of 5.22 [23]. This supports the claim that disabled subjects are more susceptible to caries than unaffected people, and their caries involvement is more severe. But in our study, the low prevalence could be explained by the size of our workforce, which was convenient. It should also be emphasized that the dental involvement concerned all degrees of severity of cerebral palsy, because children with the less severe forms of cerebral palsy tended to take care of brushing their teeth too early teeth despite lack of skill.

Regarding the correlation between degree of severity of BMI and gingivitis, we found that BMI severity level I according to the "GMFCS" was frequently associated with the occurrence of dental caries with a significance level $p=0.001$. While in the study by Sedky Nabila in 2018 the DMFT score for older children was influenced by the score at the "GMFCS", where children with reduced mobility or who could use electric mobility (level IV), or transported in a manual wheelchair (level V) were 26.3 times more likely to have dental caries than the rest of the children [24]. The difference to the difficulties of those around them, to transport them to the dental office given their equipment. The same cause can justify the low regularity and effectiveness of oral care at home.

A significant association ( $\mathrm{p}=0.001)$ was noted between BMI severity level 1 according to "GMFCS" and dental caries with a value of $p=0.001$. These results contradicted those of Guare $\mathrm{R}$ et al in the United States [25] and Dos Santos MT et al in Brazil [20] which meant that in young participants, the motor development milestone affects the DMFT score, where the children who sat supported had no neck support and those who were supported standing had 21.6 times more dental caries than children who sat and walked alone. While the DMFT score for older children was influenced by the "GMFCS", with a worse score in more severely affected subjects.

\section{CONCLUSION}

Patients with cerebral palsy present with oral pathologies such as gingivitis and dental caries as well as oral-motor disorders such as drooling, bruxism, primary swallowing, labial and/or lingual incompetence and naso-motor breathing oral. These oral conditions and oral disturbances are significantly related to the severity of the patient's disability.

\section{State of current knowledge on the subject}

- Oral diseases and loss of oral-motor ability may exist in patients with cerebral palsy, and have a negative impact on oral health and at the functional level;

- Specific care is often necessary for these parents;

- The question is insufficiently studied in Africa.

\section{Contribution of our study to knowledge}

- More focused of the problem in our context;

- This study provides us with elements of advocacy for the objective improvement of the care offered to this category of patients who are often marginalized.

Conflicts of interest: The authors declare no conflict of interest.

\section{Author contributions}

All authors contributed to the realization of this study. The authors also declare that they have read and approved the final version of the manuscript.

\section{Thanks}

To the Directors of the Mother and Child Center of the Chantal Biya Foundation and CNRPH. From Etoug-Ebe. Thank you for having accepted that we conduct our study in your hospital formations in strict compliance with ethics and medical secrecy. Our gratitude, to the Info Maladie Rare platform for its scientific and financial support in work related to rare, orphan, immuno-congenital and complex diseases in Cameroon.

\section{REFERENCES}

1. Cristina Victorio. Cerebral palsy (CMI). (2021). Children's health issues [Internet]. MSD Manuals for Consumers. Available on: https://www.msdmanuals.com/fr/accueil/probl\%C3 $\%$ A8mes-de sant\%C3\%A9infantiles/disordersneurological-in-thechild/disability\%C3\%A9motor-c\% C3\%A9r\%C3\%A9brale-imc.

2. Lefton-Greif, M. A. (2008). Pediatric dysphagia. Physical Medicine and Rehabilitation Clinics, 19(4), 837-851.

3. Arvedson, J. C. (2008). Assessment of pediatric dysphagia and feeding disorders: clinical and instrumental approaches. Developmental disabilities research reviews, 14(2), 118-127.

4. Mbassi Awa, H. D., Bekono, A., Tamgnoue, G. A., Messanga, C. B., \& Ndombo, P. O. K. (2018). Oral Hygiene, Clinical Forms of Carious Lesions and Periodontal Diseases in Disabled Children in Two Specialized Centers in Yaoundé. Health Science Dis, 19(1(Suppl)). $\quad$ https://www.hsdfmsb.org/index.php/hsd/article/view/987

5. Johnson, A. (2002). Prevalence and characteristics of children with cerebral palsy in Europe. Developmental medicine and child neurology, 44(9), 633-640.

6. Westbom, L., Hagglund, G., \& Nordmark, E. (2007). Cerebral palsy in a total population of 4-11 
year olds in southern Sweden. Prevalence and distribution according to different $\mathrm{CP}$ classification systems. BMC pediatrics, 7(1), 1-8.

7. Yeargin-Allsopp, M., Braun, K. V. N., Doernberg, N. S., Benedict, R. E., Kirby, R. S., \& Durkin, M. S. (2008). Prevalence of cerebral palsy in 8-yearold children in three areas of the United States in 2002: a multisite collaboration. Pediatrics, 121(3), 547-554

8. Jarl, J., \& Alriksson-Schmidt, A. (2021). School outcomes of adolescents with cerebral palsy in Sweden. Developmental Medicine \& Child Neurology, 63(4), 429-435.

9. Mert, G. G., Incecik, F., Altunbasak, S., Herguner, O., Mert, M. K., Kiris, N., \& Unal, I. (2011). Factors affecting epilepsy development and epilepsy prognosis in cerebral palsy. Pediatric neurology, 45(2), 89-94.

10. Benfer, K. A., Weir, K. A., Bell, K. L., Ware, R. S., Davies, P. S., \& Boyd, R. N. (2013). Oropharyngeal dysphagia and gross motor skills in children with cerebral palsy. Pediatrics, 131(5), e1553-e1562.

11. Pinto, V. V., Alves, L. A. C., Mendes, F. M., \& Ciamponi, A. L. (2016). The nutritional state of children and adolescents with cerebral palsy is associated with oral motor dysfunction and social conditions: a cross sectional study. BMC neurology, 16(1), 1-7.

12. Santos, M. T. B. R., Manzano, F. S., Ferreira, M. C. D., \& Masiero, D. (2005). Development of a novel orofacial motor function assessment scale for children with cerebral palsy. Journal of dentistry for children, 72(3), 113-118.

13. Miamoto, C. B., Ramos-Jorge, M. L., Pereira, L. J., Paiva, S. M., Pordeus, I. A., \& Marques, L. S. (2010). Severity of malocclusion in patients with cerebral palsy: determinant factors. American Journal of Orthodontics and Dentofacial Orthopedics, 138(4), 394-e1.

14. Tahmassebi, J. F., \& Luther, F. (2004). Relationship between lip position and drooling in children with cerebral palsy. European journal of paediatric dentistry, 5, 151-156.

15. Erasmus, C. E., Van Hulst, K., Rotteveel, L. J., Jongerius, P. H., Van Den Hoogen, F. J., Roeleveld, N., \& Rotteveel, J. J. (2009). Drooling in cerebral palsy: hypersalivation or dysfunctional oral motor control?. Developmental Medicine \&
Child Neurology, 51(6), 454-459.

16. Ortega, A. O. L., Guimarães, A. S., Ciamponi, A. L., \& Marie, S. K. N. (2007). Frequency of parafunctional oral habits in patients with cerebral palsy. Journal of oral rehabilitation, 34(5), 323328.

17. Botti Rodrigues Santos, M. T., Cristina Duarte Ferreira, M., de Oliveira Guaré, R., Sergio Guimarães, A., \& Lira Ortega, A. (2015). Teeth grinding, oral motor performance and maximal bite force in cerebral palsy children. Special Care in Dentistry, 35(4), 170-174.

18. Peres, A. C. D., Ribeiro, M. O., Juliano, Y., César, M. F., \& Santos, R. C. D. A. (2007). Occurrence of bruxism in a sample of Brazilian children with cerebral palsy. Special Care in Dentistry,27(2), 73-76.

19. Ch, P., Adlakha, V. K., \& Joshi, J. L. (2011). Oral status of a group of cerebral palsy children. Journal of Dentistry and Oral Hygiene, 3(2), 18-21.

20. Dos Santos, M. T. B. R., \& Nogueira, M. L. G. (2005). Infantile reflexes and their effects on dental caries and oral hygiene in cerebral palsy individuals. Journal of oral rehabilitation, 32(12), 880-885.

21. Nqcobo, C. B., Yengopal, V., Rudolph, M. J., Thekiso, M., \& Joosab, Z. (2012). Dental caries prevalence in children attending special needs schools in Johannesburg, Gauteng Province, South Africa. South African Dental Journal, 67(7), 308313.

22. Chand, B. R., Kulkarni, S., Swamy, N. K., \& Bafna, Y. (2014). Dentition status, treatment needs and risk predictors for dental caries among institutionalised disabled individuals in central India. Journal of clinical and diagnostic research: JCDR, 8(9), ZC56-59.

23. Kamaté, D. (2015). Evaluation of the oral condition in mental patients in the Psychiatry Department of the CHU du Point G about 130 cases, Available on: https://www.bibliosante.ml/handle/123456789/992

24. Sedky, N. A. (2018). Assessment of oral and dental health status in children with cerebral palsy: An exploratory study. International journal of health sciences, 12(1), 4-14.

25. Ciamponi, A. L. (2003). Dental caries prevalence in the primary dentition of cerebral-palsied children. The Journal of clinical pediatric dentistry, 27(3), 287-292. 